\section{Magnetic Resonance Imaging for the in Vivo Evaluation of Gastric-Retentive Tablets}

\author{
Andreas Steingoetter, ${ }^{1,5}$ Dominik Weishaupt, ${ }^{2}$ \\ Patrick Kunz, ${ }^{3}$ Karsten Mäder, ${ }^{3}$ Hans Lengsfeld, ${ }^{3}$ \\ Miriam Thumshirn, ${ }^{4}$ Peter Boesiger, ${ }^{1}$ Michael Fried, ${ }^{4}$ \\ and Werner Schwizer ${ }^{4}$
}

Received April 23, 2003; accepted September 3, 2003

\begin{abstract}
Purpose. To develop a magnetic resonance imaging (MRI) technique for assessing in vivo properties of orally ingested gastric-retentive tablets under physiologic conditions.

Methods. Tablets with different floating characteristics (tablet $A-C$ ) were marked with superparamagnetic $\mathrm{Fe}_{3} \mathrm{O}_{4}$ particles to analyze intragastric tablet position and residence time in human volunteers. Optimal $\mathrm{Fe}_{3} \mathrm{O}_{4}$ concentration was determined in vitro. Intragastric release characteristic of one slow-release tablet (tablet $D$ ) was analyzed by embedding gadolinium chelates (Gd-DOTA) as a drug model into the tablet. All volunteers underwent MRI in the sitting position. Tablet performance was analyzed in terms of relative position of tablet to intragastric meal level (with $100 \%$ at meal surface), intragastric residence time ( $\mathrm{min})$ and Gd-DOTA distribution volume (\% of meal volume).

Results. Intragastric tablet floating performance and residence time of tablets (tablet $A-D$ ) as well as the intragastric Gd-DOTA distribution of tablet $D$ could be monitored using MRI. Tablet floating performance was different between the tablets $(A, 93 \%(95-9 \%) ; B$, $80 \%(80-68 \%) ; C, 38 \%(63-32 \%) ; \mathrm{p}<0.05)$. The intragastric distribution volume of Gd-DOTA was $19.9 \%$ proximally and $35.5 \%$ distally.

Conclusions. The use of MRI allows the assessment of galenic properties of orally ingested tablets in humans in seated position.
\end{abstract}

KEY WORDS: human stomach; drug delivery systems; floating tablet; superparamagnetic contrast marker; Gd-DOTA; intragastric tablet performance; seated magnetic resonance imaging.

\section{INTRODUCTION}

The gastrointestinal tract is still the preferred site for the delivery of therapeutic agents to the human body. Gastricretentive oral dosage forms designed to prolong gastric residence time and to control drug delivery have gained increasing interest $(1,2)$. By combining prolonged gastric residence time and controlled release characteristics gastric-retentive drug delivery systems improve the bioavailability of drugs and may lead to a reduction of drug toxicity by avoiding uncontrolled plasma peak concentrations $(3,4)$.

The assessment of the in vivo performance is important for any pharmaceutical dosage form when designing a new

\footnotetext{
${ }^{1}$ Biophysics group, Institute of Biomedical Engineering, University and ETH Zurich Gloriastrasse, 35 CH-8092, Zurich, Switzerland.

${ }^{2}$ Department of Radiology, University Hospital Zurich, Switzerland.

${ }^{3}$ F. Hoffmann-LaRoche, Basel, Switzerland.

${ }^{4}$ Department of Gastroenterology, University Hospital Zurich, Switzerland.

${ }^{5}$ To whom correspondence should be addressed. (e-mail: steingoetter@biomed.ee.ethz.ch)
}

drug, especially in case of gastric-retentive drug formulations. So far, $\gamma$-scintigraphy is the most widely used technique for this purpose. The technique is based on radiolabeling the drug dosage form under investigation, which can be monitored subsequently over time $(5,6)$. The main drawbacks of $\gamma$-scintigraphy are the associated ionizing irradiation for the patient, the limited topographic information and low resolution inherent to the technique and the complicated and expensive preparation of radiopharmaceuticals.

In the last couple of years, magnetic resonance imaging (MRI) was shown by our group (7-11) and others (12-16) to be a novel, valuable tool in gastrointestinal research for the analysis of gastric emptying, motility, and intragastric distribution of macronutrients and drug models. The use of MRI in studying oral drug delivery is limited so far, although the inherent advantages of MR imaging are potentially very favorable for this purpose. These advantages include high soft tissue contrast, high temporal and spatial resolution, as well as the lack of ionizing irradiation. Also, harmless paramagnetic and superparamagnetic MR imaging contrast agents can be applied to specifically enhance or suppress signals of fluids and tissues of interest and thus permit better delineation and study of organs.

The purpose of this study is to develop and implement an MRI technique that allows the assessment of the in vivo performance of ingested slow-release gastric-retentive tablets in asymptomatic volunteers. Volunteers were investigated in the seated position using an open-configuration MRI system. Therefore, gastric-retentive tablets were labeled with superparamagnetic iron oxide $\left(\mathrm{Fe}_{3} \mathrm{O}_{4}\right)$ particles as tablet marker or were loaded with paramagnetic gadolinium $(\mathrm{Gd})$ chelates (Gd-DOTA) as drug model to enable in vivo monitoring of tablets with MRI.

\section{METHODS}

An initial in vitro study was conducted to evaluate the use of superparamagnetic $\mathrm{Fe}_{3} \mathrm{O}_{4}$ particles as tablet marker in MRI. Furthermore, a pulverized form of the paramagnetic Gd-DOTA was prepared to be embedded into the matrix of a slow-release floating tablet and to serve as water soluble model drug.

In the following in vivo study, $\mathrm{Fe}_{3} \mathrm{O}_{4}$ marked floating tablets of different density were prepared and analyzed for intragastric position in the human food-filled stomach. The drug model release and distribution from a slow-release floating tablet containing Gd-DOTA were also investigated in human volunteers.

\section{PREPARATIONS AND IN VITRO STUDIES}

\section{$\mathrm{Fe}_{3} \mathrm{O}_{4}$ as Tablet Marker}

A gastric-retentive floating tablet was marked with different concentrations of $\mathrm{Fe}_{3} \mathrm{O}_{4}$ (i.e. $0 \%, 0.05 \%, 0.1 \%, 0.5 \%$, $\left.1 \% \mathrm{Fe}_{3} \mathrm{O}_{4}\right)$ in-house at the pharmacy of the University Hospital to determine optimal $\mathrm{Fe}_{3} \mathrm{O}_{4}$ concentration for tablet labeling. The tablets were imaged in water at $\mathrm{pH} 4.5$ and $37^{\circ} \mathrm{C}$ using a 0.5 T open-configuration MRI system (Signa SP, General Electric Medical Systems, Milwaukee, WI, USA). Sequence parameter were chosen to resemble the in vivo situ- 
ation $\left(\mathrm{T}_{1}\right.$-weighted fast spoiled gradient echo (FSPGR) technique; 30 sagittal image slices; repetition time ms/echo time ms 150/8; field of view, $280 \mathrm{~mm}$; flip angle, $60^{\circ}$; matrix, $256 \times$ 160; slice thickness, $8 \mathrm{~mm}$; interslice gap, $0 \mathrm{~mm}$ ). Images were acquired at 30-min intervals for at most 4 hours.

Susceptibility artifacts originated by the $\mathrm{Fe}_{3} \mathrm{O}_{4}$ marked tablets were quantified as the largest diameter of the circular shaped artifact area. The artifact diameter remained constant over the complete study period for each $\mathrm{Fe}_{3} \mathrm{O}_{4}$ concentration.

The effect of $\mathrm{Fe}_{3} \mathrm{O}_{4}$ tablet concentration on the artifact diameter was analyzed (Fig. 1) and agreed well with theory (17). The $\mathrm{Fe}_{3} \mathrm{O}_{4}$ concentration of $1 \%$ per tablet volume (4 $\mathrm{mg}$ ) was chosen to be further evaluated in vivo.

\section{Gd-DOTA as Drug Model}

Recent studies conducted in our group demonstrated that Gd-chelates as a drug model inside a gelatin capsule allow the analysis of distribution and mixing of the drug model in the food-filled human stomach $(10,11)$. Due to the higher molecular weight compared to water, Gd chelates might not represent an ideal drug model. But since convection and shear are the dominant mixing forces in the food filled stomach diffusion and gravity are assumed to have negligible effects on the intragastric distribution of the drug model. To apply Gd chelates as drug model inside a tablet, it is necessary to prepare a pulverized form of the aqueous $\mathrm{Gd}$ contrast agent. Therefore, DOTAREM ${ }^{\circledR}$ (Laboratoire Guerbet, Aulnay-Sous-Bois, France) with concentration of 0.5 $\mathrm{mmol} / \mathrm{ml}$ was wet granulated with metolose powder, sieved and dried overnight at $50^{\circ} \mathrm{C}$ to derive the pulverized form of DOTAREM ("dried Gd-DOTA"). DOTAREM ${ }^{\circledR}$ is a commercially available and clinically widely used extracellular paramagnetic contrast agent for intravenous application in MRI angiography. Its intragastric stability and low toxicity as gastrointestinal contrast agent has been shown previously (7).

Before administration of the Gd-DOTA (Gd-tetraazacyclododecane tetra-acetic acid) tablets, the dried GdDOTA had to be tested for intragastric stability. The test

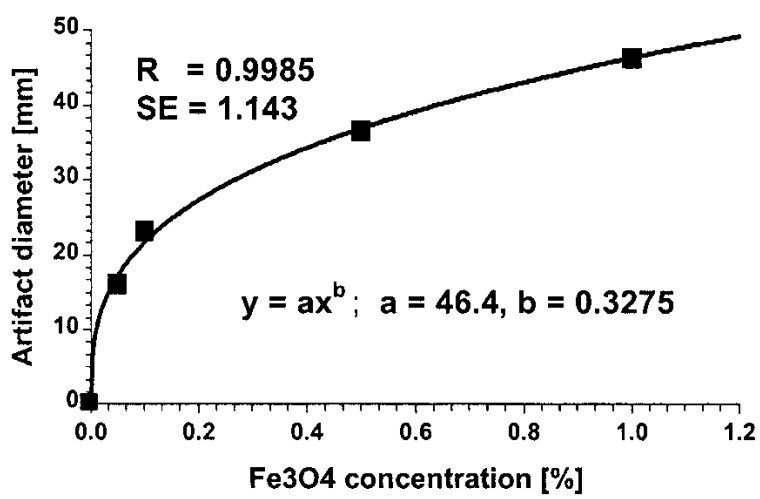

Fig. 1. The graph describes the dependency of the originated susceptibility artifact diameter in the MRI images on the $\mathrm{Fe}_{3} \mathrm{O}_{4}$ concentration in the tablet. There was a strong increase in artifact diameter between concentrations of $0.05 \%(0.2 \mathrm{mg})$ and $0.1 \%(0.4 \mathrm{mg})$. At concentrations of $0.5 \%(2 \mathrm{mg})$ and $1 \%(4 \mathrm{mg})$ the increase in artifact diameter flattened. The filled squares ( $\square$ ) indicate the measured artifact diameters. The solid curve represents the calculated power fit (y $\left.=a x^{b}\right)$. Function parameters $a$ and $b$, correlation coefficient $(\mathrm{R})$ and standard error (SE) of the power fit are listed. revealed that after $36 \mathrm{~h}$ of incubation in artificial gastric juice at $37^{\circ} \mathrm{C}$, no difference of free $\mathrm{Gd}$ was present for the two preparations.

\section{IN VIVO STUDY}

The study was approved by the Institutional Review Board and informed consent was obtained by all volunteers who participated in the study.

\section{Tablet Preparation}

Three floating tablets (tablets $A, B, C$ ) of different density were marked with $1 \%$ of $\mathrm{Fe}_{3} \mathrm{O}_{4}$ per volume unit. This concentration permitted a clear distinction between the tablet and other signal voids such as intragastric air or residual solids of the ingested meal. Tablets $A$ and $B$ had different tablet compositions but were formed with equal compression force by an hydraulic press. Tablet $C$ had the same tablet composition as tablet $B$, but was formed with a higher compression force. A fourth slow-release floating tablet (tablet $D$ ) containing the dried Gd-DOTA was prepared. The dried GdDOTA was embedded at a concentration of $31 \%$ of total tablet volume $(155 \mathrm{mg})$ in the tablet. This tablet (tablet $D$ ) was also formed using the hydraulic press. Detailed information on tablet composition and formation is listed in Table I.

\section{Study Design}

The four tablets $(A, B, C$ and $D)$ were evaluated in vivo. Each tablet formulation was administered to five healthy male volunteers (age: $19-38$ years; BMI: $19.4-26.3 \mathrm{~kg} / \mathrm{m}^{2}$ ). All volunteers had no history of gastrointestinal symptoms or abdominal surgery, and all volunteers fasted at least $6 \mathrm{~h}$ prior to the administration of the tablets. Tablets were ingested after intake of a standardized semi-solid test meal consisting of hamburger $(130 \mathrm{~g})$, french fries $(160 \mathrm{~g})$, string beans $(120 \mathrm{~g})$, fruit salad $(200 \mathrm{ml})$, orange juice $(100 \mathrm{~mL})$, and water $(300$ $\mathrm{mL})$. The total energy content of the meal was $922 \mathrm{kcal}$. After tablet ingestion, all subjects underwent MRI using a $0.5 \mathrm{~T}$ open-configuration MRI system (Signa SP, General Electric Medical Systems, Milwaukee, WI, USA). Subjects were po-

Table I.

\begin{tabular}{|c|c|c|c|c|}
\hline Composition & A & $\mathrm{B}$ & $\mathrm{C}$ & $\mathrm{D}$ \\
\hline Magnetit $\left(\mathrm{Fe}_{3} \mathrm{O}_{4}\right)$ & 1 & 1 & 1 & - \\
\hline Citronensremonohydrat & 2.5 & 2.5 & 2.5 & 2.5 \\
\hline $\mathrm{NaHCO}_{3}$ & 2.5 & 2.5 & 2.5 & 2.5 \\
\hline PVP K30* & 1 & 1 & 1 & 1 \\
\hline Encompress & - & - & - & - \\
\hline Metolose 90SH-4000SR & 82 & 46 & 46 & 62 \\
\hline Mg-Stearat & 1 & 1 & 1 & 1 \\
\hline Talkum & - & - & - & - \\
\hline Lactose & 10 & 26 & 26 & - \\
\hline Avicel PH 102 & - & 20 & 20 & - \\
\hline Dried Gd-DOTA & - & - & - & 31 \\
\hline \multicolumn{5}{|l|}{ Formation } \\
\hline \multicolumn{5}{|l|}{ Compression force } \\
\hline$[\mathrm{KN} / 5 \mathrm{~s}]$ & 3 & 3 & 6 & 3 \\
\hline Tool size $[\mathrm{mm} \times \mathrm{mm}]$ & $15 \times 6.9$ & $15 \times 6.9$ & $15 \times 6.9$ & $15 \times 6.9$ \\
\hline Tablet weight [mg] & 400 & 400 & 400 & 400 \\
\hline
\end{tabular}


sitioned in sitting position and sagittal volume scans covering the total gastric region were performed immediately after tablet ingestion and at 30-min intervals thereafter for a period of 4 hours. Sequence parameters of the scans were: T1-weighted FSPGR technique; 24 sagittal slices; field of view, $280 \mathrm{~mm}$; flip angle, $60^{\circ}$; matrix, $256 \times 160$; slice thickness, $8 \mathrm{~mm}$; interslice gap, $0 \mathrm{~mm}$; repetition time ms/echo time ms of $150 / 8$ for tablets $A-C$; and $68 / 8$ for tablet $D$.

\section{ANALYSIS}

\section{Image Analysis}

The intragastric position of tablets $A, B$, and $C$ was determined based on the induced susceptibility artifacts in the sagittal MRI images. Gastric residence time $\left(\mathrm{T}_{\max }\right)$ of the tablets was defined as the time between first and last detection of the tablet in the stomach. To analyze gastric emptying of the meal, gastric content was outlined in every image of a volume scan. The area of the outlined gastric content was calculated and multiplied with the slice thickness to obtain the volume of the gastric content as function of time. To determine tablet-floating performance, the location of the tablet within the stomach was analyzed at each time point based on the volume scan. Intragastric tablet location was calculated relative to the meal surface in the proximal stomach. Floating performance was defined as the ability of the tablet to swim on the meal surface, expressed as a percentage. A floating performance of $100 \%$ corresponded to the tablet located on the meal surface, whereas $0 \%$ corresponded to a tablet position at the bottom of the stomach (Fig. 2a).

Absolute (ml) and relative (\%) distribution volumes of the released Gd-DOTA from tablet $D$ were analyzed in the total, proximal, and distal stomach. Proximal volume was defined as the volume that was outlined between the most left lateral point of the stomach and the incisura of the lesser curvature (Fig. 2a). Distal volume was defined as the volume between incisura and pylorus. An intensity threshold was manually selected for each segmented volume of each subject. The total volume inside the outlined gastric region with an intensity above the chosen threshold corresponded to the absolute Gd-DOTA distribution volume in ml (Fig. 2b). The relative Gd-DOTA distribution volume (\%) was defined as the absolute distribution volume divided by the meal volume of the respective gastric region. Analysis was performed using a home-built software package implemented in IDL 5.4 (Research Systems Inc., Boulder, CO, USA).

\section{Three-dimensional (3D) Visualization}

The stomach, the tablet-induced artifact and the GdDOTA distribution volume (only for tablet $D$ ) were visualized in 3D for descriptive analysis of intragastric tablet floating performance and drug model distribution. The visualization was performed by a surface rendering, using IsoSurf v1.5d (http://svr-www.eng.cam.ac.uk/ gmt11, Dr. Graham Treece) for mesh generation and 3Space Assistant from TGS Europe (Merignac Cedex, France) for viewing.

\section{Statistics}

Half time of gastric meal emptying ( $\mathrm{T} 50 \%$ ), gastric residence time $\left(\mathrm{T}_{\max }\right)$, and floating performance of tablets $A, B$, a.

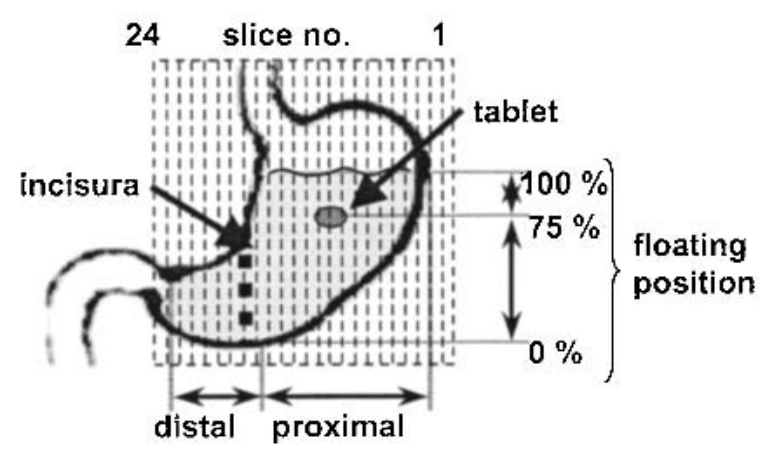

b.

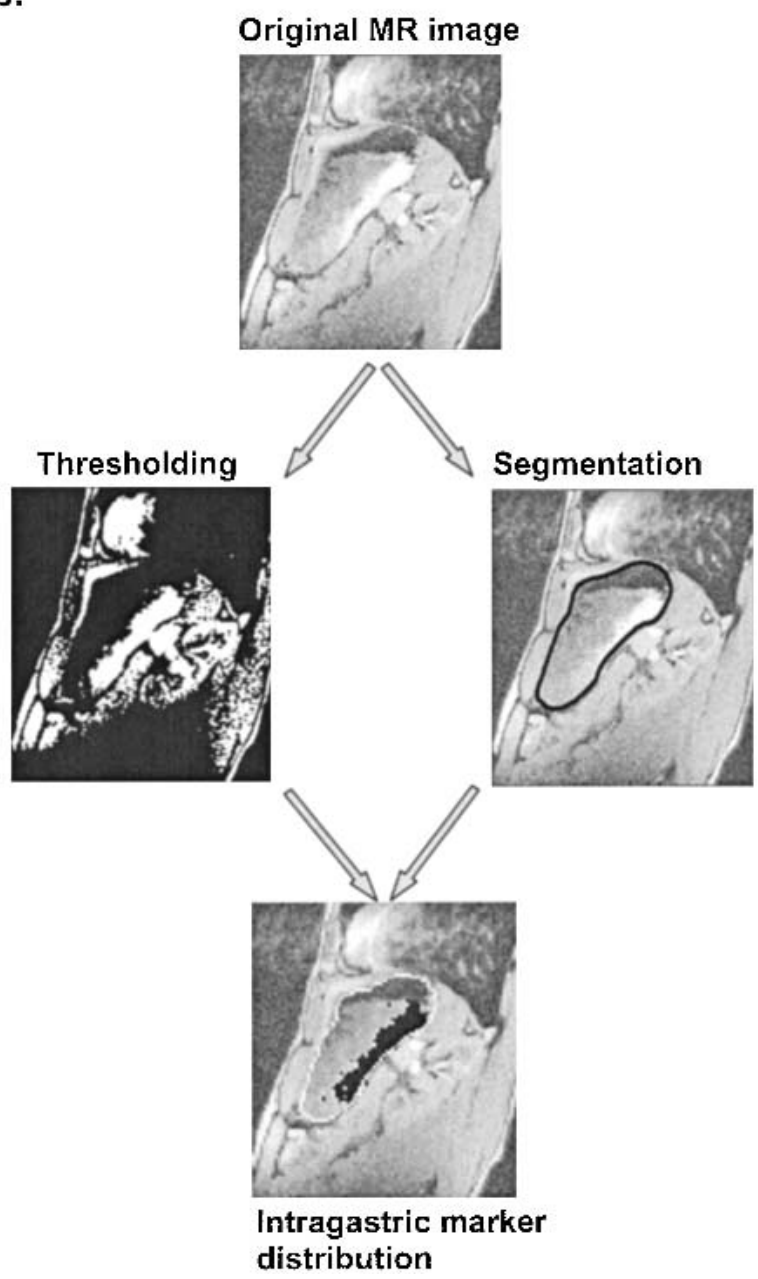

Fig. 2. (a) Sketch of coronal view of the stomach illustrating the calculation of tablet floating performance based on intragastric tablet position. Sagittal MRI image planes (slice no. 1-24) are depicted as thin dashed lines. The gastric incisura dividing proximal and distal stomach is indicated as bold dotted line. (b) Flow chart that illustrates the technique for calculation of the intragastric distribution volume of the released Gd-DOTA. After segmentation of the stomach volume and applying an image intensity threshold the intragastric marker distribution volume was calculated. 


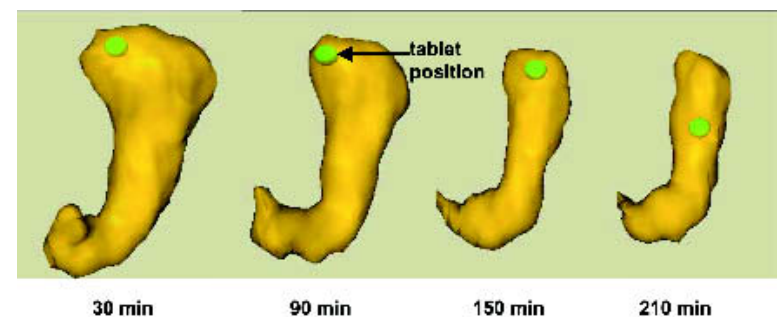

Fig. 3. Three-dimensional visualization of stomach volume and tablet position at times $\mathrm{t}=30,90,150$, and $210 \mathrm{~min}$ of a volunteer that ingested tablet $A$. In this volunteer, the tablet was constantly swimming on the meal surface (floating performance of $97 \%$ ).

and $C$ were statistically compared using Analysis of Variance (ANOVA) with repeated measures. The Tukey HSD (honest significant difference) post-hoc test was used for inter-group comparison. For tablet $D$, absolute and relative Gd-DOTA distribution volumes were statistically analyzed also using ANOVA. Data were expressed in median (interquartile ranges). A $p$ value of 0.05 was considered statistically significant.

\section{RESULTS}

Susceptibility artifacts originated from the $1 \% \mathrm{Fe}_{3} \mathrm{O}_{4}$ marked tablets $A, B$, and $C$ allowed detection of intragastric tablet position in all subjects and at all time points. Figure 3 illustrates the $3 \mathrm{D}$ visualization of the stomach volume and tablet position at different time points after oral ingestion. Intragastric floating position of the tablet and the reduction in proximal stomach volume during the emptying process could clearly be recognized using the 3D images in all volunteers.

Gastric meal emptying curves are plotted in Fig. 4. There was no difference $(\mathrm{p}=0.5)$ in $\mathrm{T} 50 \%$ among the volunteer groups that ingested tablets $A, B$, and $C: A, 89 \min$ (87-99 min); $B, 114 \mathrm{~min}$ (109-125 $\mathrm{min}) ; C, 121 \mathrm{~min}$ (106-147 min). No difference $(\mathrm{p}=0.6)$ in $\mathrm{T}_{\max }$ was detected between the three tablets: $A$, $240 \mathrm{~min}$ (240-240 $\mathrm{min}$ ); B, $240 \mathrm{~min}$ (210-240 $\min$ ); $C, 150 \mathrm{~min}$ (150-210 $\mathrm{min}$ ). Tablet floating performance over time for each of the three tablets is plotted in Fig. 5 a to c. An overall difference $(\mathrm{p}<0.05)$ in floating performance was detected between the tablets: $A, 93 \%$ (95-90\%); B, 80\%

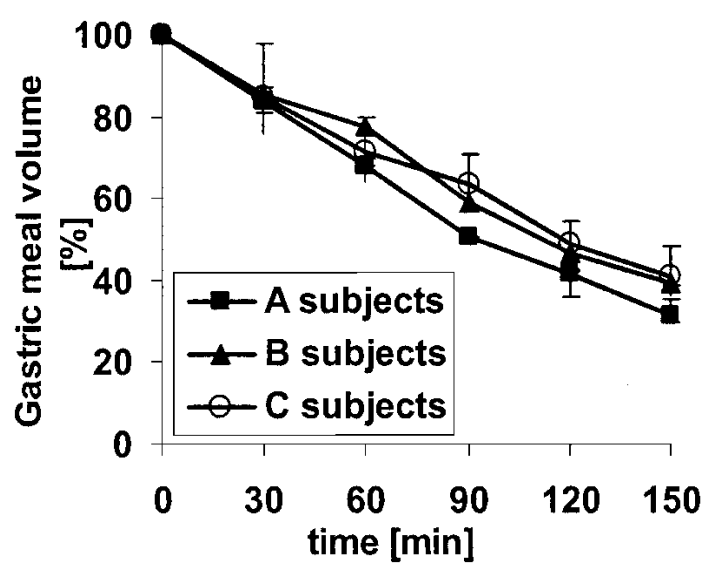

Fig. 4. (a) Gastric meal emptying curves of the three groups of volunteers that tested tablets $A, B$ and $C$. Data are plotted as median (interquartile range).
(80-68\%); $C, 38 \%(63-32 \%)$. The post-hoc test showed a significant difference $(\mathrm{p}<0.05)$ only between tablets $A$ and $C$. Intragastric distribution of the Gd-DOTA released from tablet $D$ and the intragastric position of tablet $D$ could be detected and analyzed in all five subjects (Fig. 6a). The dynamics of total intragastric Gd-DOTA distribution could be clearly visualized using the 3D technique (see Fig. 6b). The Gd-DOTA dispersed along the posterior gastric wall into the distal stomach bypassing most of the meal in the fundus. In the distal part of the stomach, the dissolved Gd-DOTA was better mixed with gastric content. The relative and absolute Gd-DOTA distribution volumes are plotted over time for total, proximal and distal stomach volume in Figs. 7a and 7b. Relative as well as absolute Gd-DOTA distribution volumes showed a difference between the two stomach compartments. Relative distribution volumes $(p=0.04)$ were $9 \%(6-12 \%)$ in the proximal and $16 \%(9-33 \%)$ in the distal stomach. Abso-
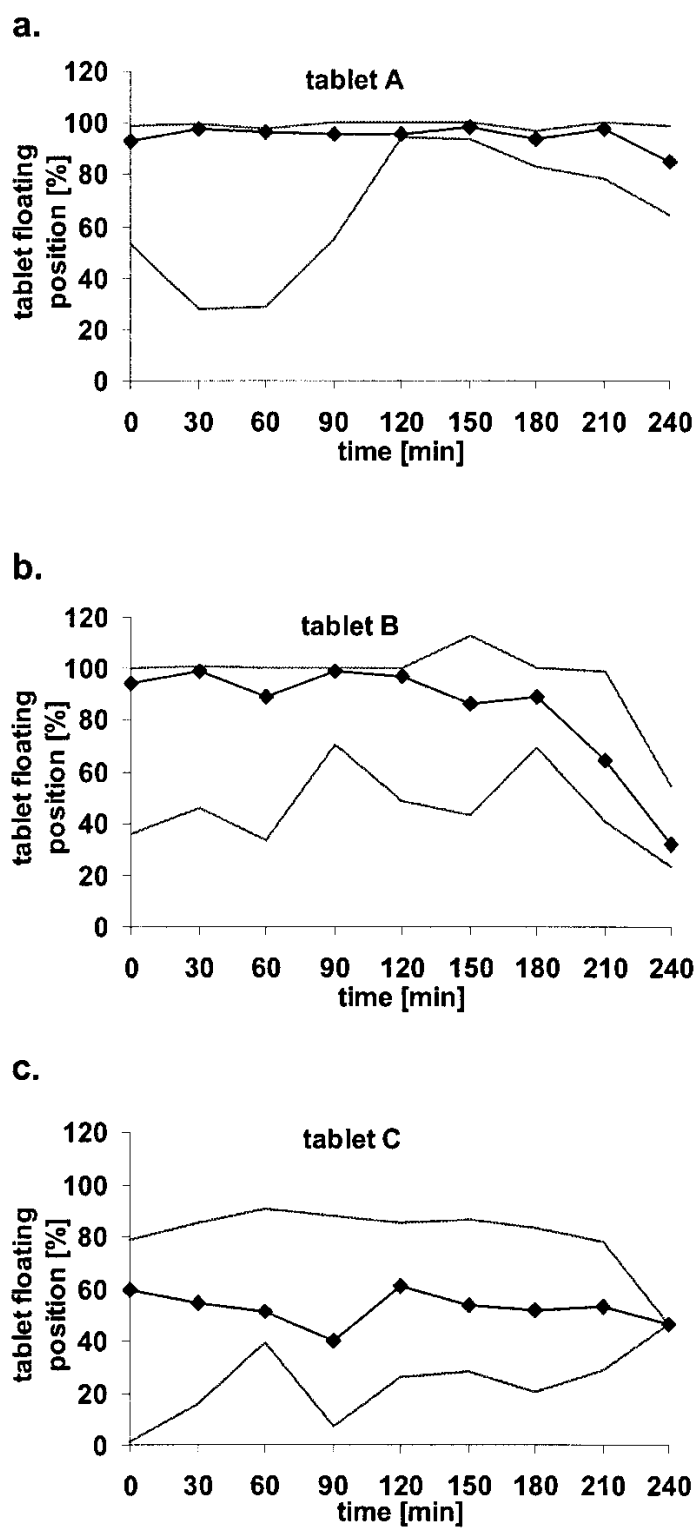

Fig. 5. (a-c) Tablet floating performance over study period in $\%$ for the three tablet formulations $A, B$ and $C$ as measured in the volunteers. Data are plotted as median (min to max range). 


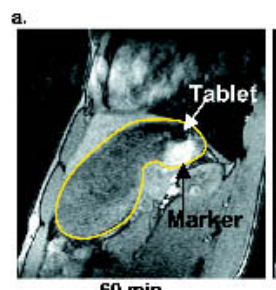

$60 \mathrm{~min}$
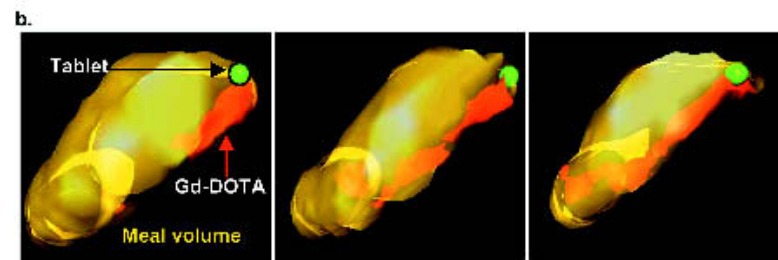

Fig. 6. (a) Sagittal $T_{1}$-weighted fast spoiled gradient echo $M R$ images $\left(8 / 68 \mathrm{~ms}\right.$, flip angle of $\left.60^{\circ}\right)$ of the proximal stomach at times $t=60$, 120 and $180 \mathrm{~min}$ showing the release and intragastric distribution of Gd-DOTA in a volunteer. Stomach volume is outlined and the GdDOTA distribution volume as bright signal inside the segmented area is indicated in the MR images (arrow). (b) 3D visualization of the measured volume scans from 6a depicting the dynamic of intragastric Gd-DOTA distribution volume in the meal volume.

lute distribution volumes $(\mathrm{p}=0.01)$ were $45 \mathrm{ml}(27-54 \mathrm{ml})$ in the proximal and $20 \mathrm{ml}(12-29 \mathrm{ml})$ in the distal stomach. Maximum relative Gd-DOTA distribution volumes were $20 \%$ in the proximal and $36 \%$ in the distal stomach. Maximum absolute Gd-DOTA distribution volumes were $54 \mathrm{ml}$ in the proximal and $31 \mathrm{ml}$ in the distal stomach. The maximum distribution of GD-DOTA into the meal was reached after 90 $\min (90-180 \mathrm{~min})$.

The T $50 \%$ for volunteers that tested tablet $D$ was 116 $\min$ (79-123 min). The $\mathrm{T}_{\max }$ of tablet $D$ was $240 \min (240-240$ $\min$ ). The floating performance over study period was $94 \%$ (87-97\%). However, floating power of tablet $D$ decreased after $180 \mathrm{~min}$ in three subjects.

\section{DISCUSSION}

This study showed that the labeling of gastric-retentive tablets with $\mathrm{Fe}_{3} \mathrm{O}_{4}$ is feasible and that marked tablets can be visualized using MRI. By using an open-configuration MRI system, intragastric position of tablets could be monitored in seated volunteers. This permitted analysis and quantification of tablet residence time and floating performance in the human stomach under physiologic conditions. Furthermore, the study demonstrated that the intragastric release of GdDOTA as drug model within a gastric-retentive tablet can reliably be monitored using MRI, allowing the analysis of intragastric Gd-DOTA distribution volumes.

To the best of our knowledge, this was the first investigation demonstrating the feasibility of MRI to study the impact of formulation density and meal emptying on the dynamics and behavior of ingested gastric-retentive tablets in the human stomach. The investigation in the seated position using an open-configuration MRI system has the advantage to represent the most physiologic position for eating. As opposed to the supine position, in sitting position the intragastric air and thus the intragastric meal surface is always located in the proximal stomach. Gravity acting on a tablet floating on the meal surface is therefore confined along the long gastric axis.

So far, $\gamma$-scintigraphy is the most widely used imaging modality for in vivo investigation of the delivery and biodistribution of orally ingested drug delivery systems $(5,6)$. The strength of the scintigraphic method is the ability to quantify the marker distribution (as distribution of activity) based on the count rates in a region of interest that represent a proportion of the radioactivity administered. However, for an accurate quantification it is necessary to determine correction factors for the attenuation of the $\gamma$-rays and for the background noise. This demands for simultaneous recordings in anterior and posterior views and experimental studies using phantoms (18). In comparison, the quantification of the drug model distribution using MRI requires the assessment of a calibration curve to determine the signal enhancement of different marker concentrations in the test meal. Also, homogenous excitation and signal detection over the region of interest is favorable to avoid complex intensity correction procedures. This method has the disadvantage of not allowing simultaneous correction of signal intensity shifts due to fat or gastric secretion.

The major drawbacks of scintigraphy are the lack of soft-

a.

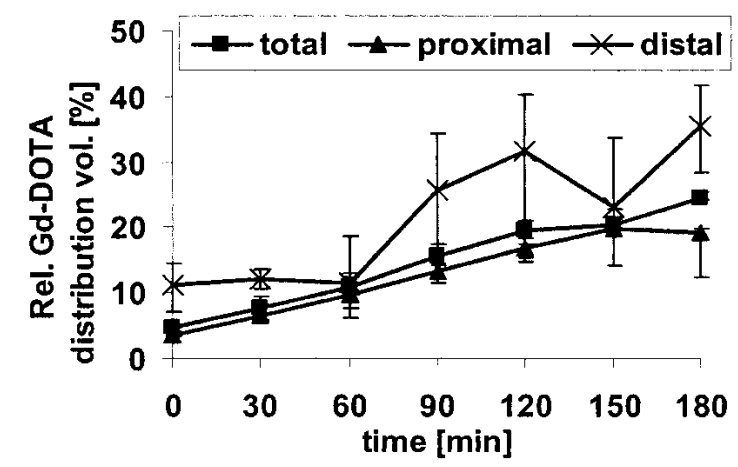

b.

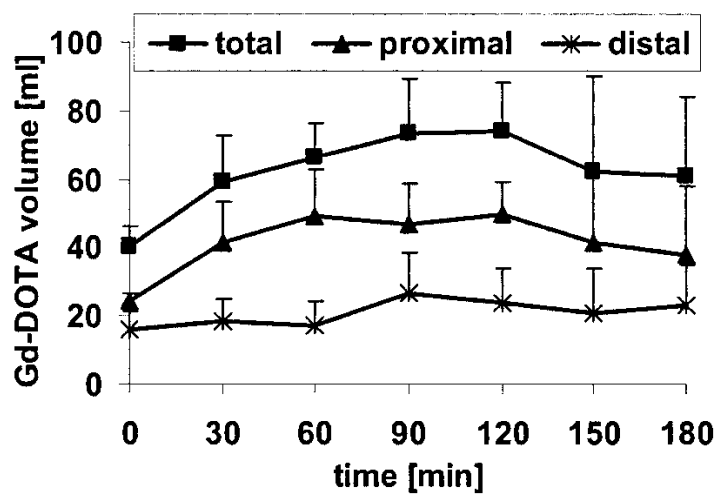

Fig. 7. (a) The graph shows the relative Gd-DOTA distribution volumes in the total, proximal, and distal stomach for tablet $D$ as measured in the human volunteers. (b) The graph shows the absolute Gd-DOTA distribution volumes in the total, proximal and distal stomach for tablet $D$ as measured in the human volunteers. Data are plotted as median (interquartile range). 
tissue contrast, the limited spatial resolution and the exposure to ionizing radiation. These limitations may be overcome with MRI. As shown in this study, a three-dimensional gastric volume data set with high spatial and temporal resolution resulting in a good image quality could be obtained in all volunteers. The technique allows for repeated imaging over the time period needed. Future studies will evaluate if the technique is also useful for simultaneous assessment of complementary physiologic data including gastric motility or gastric accommodation in sitting position. Recent studies have demonstrated the feasibility of MRI for the assessment of gastric function using a closed configuration magnet with the patient lying in supine position $(19,20)$.

For labeling the gastric-retentive tablet, we used superparamagnetic iron oxide $\left(\mathrm{Fe}_{3} \mathrm{O}_{4}\right)$ particles and gadolinium chelates (Gd-DOTA) which are both widely used for abdominal MRI (21-23), (11,24,25). The applied $\mathrm{Fe}_{3} \mathrm{O}_{4}$ (Magnetite) is used as additive (E 172) in food processing with an allowed daily intake of $0.5 \mathrm{mg} / \mathrm{kg}$. This low toxicity combined with low costs makes $\mathrm{Fe}_{3} \mathrm{O}_{4}$ the preferred MRI contrast marker for tablet labeling. The application of Gd-DOTA as non-toxic and stable gastrointestinal MRI contrast agent has been shown previously (7).

The optimal $\mathrm{Fe}_{3} \mathrm{O}_{4}$ concentration of $1 \%$ per tablet volume to label the floating tablet was determined in an initial in vitro study.

Susceptibility artifacts, revealing the intragastric position of ingested $\mathrm{Fe}_{3} \mathrm{O}_{4}$ marked tablets could be detected in all subjects and over entire study period. Good contrast between gastric content and intragastric air in the MRI images resulted in a sharp delineation of intragastric meal level allowing a reliable calculation of tablet floating performance. Tablet floating performance differed only between tablets $A$ and $C$, but with no difference in tablet residence time. The higher variability in the floating performance data of tablet $\mathrm{C}$ can be explained by the increased effect of gastric motility on tablet position. Tablets showing a floating performance of $60 \%$ or less were located within and below the gastric region of contraction wave activation. We conclude that the lower density of tablets $A$ and $B$ achieved with a compression force of $3 \mathrm{kN}$ provide better intragastric floating performance than the density of tablet $C$ (compression force $6 \mathrm{kN}$ ). The results indicate that floating performance of the tablets can be controlled effectively by adjusting the tablet composition and density.

The study has further demonstrated that the positive contrast agent Gd-DOTA embedded in a slow-release floating tablet may serve as an ionic water soluble model drug for the analysis of intragastric distribution of orally administrated drugs. Furthermore, the released Gd-DOTA allowed a semiquantitative measure of the release characteristics of the tablet. The disadvantage of Gd-DOTA as tablet marker in comparison to $\mathrm{Fe}_{3} \mathrm{O}_{4}$ is the greater volume necessary for tablet labeling ( $31 \%$ or $155 \mathrm{mg}$ Gd-DOTA vs. $1 \%$ or $4 \mathrm{mg} \mathrm{Fe}_{3} \mathrm{O}_{4}$ ). Gd-DOTA's higher ionic character and osmotic pressure also influence the characteristics of the tablet formulation and thus can strongly alter the tablet properties.

Tablet $D$ showed long gastric residence times and a good floating performance. However, a large inter-subject variance was observed in gastric meal emptying. Nevertheless, tablet floating performances and gastric residence times appeared to be unaffected by these variations. The emptying pathway of the released Gd-DOTA proceeded along the inner gastric curvature resulting in an inhomogeneous intragastric distribution. The release of Gd-DOTA from the tablet was faster than its emptying from the stomach during the first half of the study period ( $90 \mathrm{~min}$ ) as shown by the increasing absolute Gd-DOTA distribution volume in the stomach. The constant increase of relative intragastric drug model distribution volume suggested that more non-marked meal constantly emptied from the stomach while Gd-DOTA was simultaneously added to gastric content. The possibility that marked meal may have emptied more slowly from the stomach than the non-marked meal was unlikely because the drug model mixes with the liquid phase of the meal that has been shown to empty faster than the solid phase $(9,26)$. The described results are of interest for orally administered drugs that must empty together with specific macronutrients as is the case for enzyme preparations in chronic exocrine pancreatic insufficiency (27). These preparations require homogeneous mixing and simultaneous emptying with the ingested meal to achieve optimal efficacy.

The emptying pathway of the drug model along the inner gastric wall and the non-homogeneous mixing, especially in the proximal part, is in agreement with results of a previous study (11). In that paper, the higher maximum distal relative distribution volume may be explained by the fact that a liquid marker was used that was instantly released in the gastric fundus. Thus, more Gd-DOTA proceeded into the antrum and was mixed in distal meal volume. The similarity of emptying and mixing pattern of the Gd-DOTA drug model suggest that these processes might be independent of posture. This observation suggest that the inhomogeneous mixing of liquid and solid phases throughout the stomach may represent an inherent limiting factor for the efficacy of orally administered substances that depend on the interaction with specific macronutrients.

There are some limitations in the proposed approach in this study. A key shortcoming of applying MRI is the limited number of methods for nutrient and drug labeling. Ongoing intensive research on the development of new and more flexible MRI contrast agents may help to overcome these limits in the future, which may allow studies comparable to those with dual-isotope imaging (28). Another shortcoming is the limited availability of the open-configuration MRI scanner used here. However, it should be mentioned that this method could be applied to any compact clinical MRI system. In this case, the effect of posture on intragastric distribution must then be taken into account $(29,30)$.

In conclusion, our study has demonstrated that MRI is useful for assessing the in vivo properties of orally ingested gastric-retentive tablets including their floating performance and drug release characteristics. The herein proposed MRI technique may also be useful for studying the gastrointestinal pharmaco-dynamic and kinetic behavior of newly designed drugs or to evaluate existing drugs. Further studies are needed to evaluate if the technique may replace $\gamma$-scintigraphy for these purposes.

\section{ACKNOWLEDGMENTS}

We acknowledge the technical and organizational support of Karl Treiber and Bernadette Stutz. This study was supported by F. Hoffmann-LaRoche, Basel, Switzerland and the Swiss National Science Foundation (SNF grants 3254056.98 and 31-55932.98). 


\section{REFERENCES}

1. S. J. Hwang, H. Park, and K. Park. Gastric retentive drugdelivery systems. Crit. Rev. Ther. Drug Carrier Syst. 15:243-284 (1998)

2. B. N. Singh and K. H. Kim. Floating drug delivery systems: an approach to oral controlled drug delivery via gastric retention. $J$. Cont. Release 63:235-259 (2000).

3. L. Whitehead, J. T. Fell, J. H. Collett, H. L. Sharma, and A. Smith. Floating dosage forms: an in vivo study demonstrating prolonged gastric retention. J. Cont. Release 55:3-12 (1998).

4. G. Gusler, J. Gorsline, G. Levy, S. Z. Zhang, I. E. Weston, D. Naret, and B. Berner. Pharmacokinetics of metformin gastricretentive tablets in healthy volunteers. J. Clin. Pharmacol. 41: 655-661 (2001).

5. C. G. Wilson. In-vivo monitoring of dosage forms. J. Pharm. Pharmacol. 50:383-386 (1998).

6. I. R. Wilding, A. J. Coupe, and S. S. Davis. The role of gammascintigraphy in oral drug delivery. Adv. Drug Deliv. Rev. 46:103124 (2001).

7. W. Schwizer, R. Fraser, H. Maecke, K. Siebold, R. Funck, and M. Fried. Gd-DOTA as a gastrointestinal contrast agent for gastric emptying measurements with MRI. Magn. Reson. Med. 31:388393 (1994).

8. P. Kunz, C. Feinle, W. Schwizer, M. Fried, and P. Boesiger. Assessment of gastric motor function during the emptying of solid and liquid meals in humans by MRI. J. Magn. Reson. Imaging 9:75-80 (1999).

9. C. Feinle, P. Kunz, P. Boesiger, M. Fried, and W. Schwizer. Scintigraphic validation of a magnetic resonance imaging method to study gastric emptying of a solid meal in humans. Gut 44:106-111 (1999).

10. H. Faas, W. Schwizer, C. Feinle, H. Lengsfeld, C. de Smidt, P. Boesiger, M. Fried, and T. Rades. Monitoring the intragastric distribution of a colloidal drug carrier model by magnetic resonance imaging460. Pharm. Res. 18:460-466 (2001).

11. H. Faas, A. Steingoetter, C. Feinle, T. Rades, H. Lengsfeld, P. Boesiger, M. Fried, and W. Schwizer. Effects of meal consistency and ingested fluid volume on the intragastric distribution of a drug model in humans - a magnetic resonance imaging study. Aliment. Pharmacol. Ther. 16:217-224 (2002).

12. P. Boulby, P. Gowland, V. Adams, and R. C. Spiller. Use of echo planar imaging to demonstrate the effect of posture on the intragastric distribution and emptying of an oil/water meal. Neurogastroenterol. Motil. 9:41-47 (1997).

13. L. Marciani, P. Manoj, B. P. Hills, R. J. Moore, P. Young, A. Fillery-Travis, R. C. Spiller, and P. A. Gowland. Echo-planar imaging relaxometry to measure the viscosity of a model meal. $J$. Magn. Reson. 135:82-86 (1998).

14. P. Boulby, R. Moore, P. Gowland, and R. C. Spiller. Fat delays emptying but increases forward and backward antral flow as assessed by flow-sensitive magnetic resonance imaging. Neurogastroenterol. Motil. 11:27-36 (1999).

15. L. Marciani, P. A. Gowland, R. C. Spiller, P. Manoj, R. J. Moore, P. Young, S. Al-Sahab, D. Bush, J. Wright, and A. J. FilleryTravis. Gastric response to increased meal viscosity assessed by echo-planar magnetic resonance imaging in humans. J. Nutr. 130: 122-127 (2000).
16. L. Marciani, P. A. Gowland, R. C. Spiller, P. Manoj, R. J. Moore, P. Young, and A. J. Fillery-Travis. Effect of meal viscosity and nutrients on satiety, intragastric dilution, and emptying assessed by MRI. Am. J. Physiol. Gastrointest. Liver Physiol. 280:G1227G1233 (2001).

17. J. F. Schenck. The role of magnetic susceptibility in magnetic resonance imaging: MRI magnetic compatibility of the first and second kinds. Med. Phys. 23:815-850 (1996).

18. A. C. Perkins and M. Frier. Nuclear medicine techniques in the evaluation of pharmaceutical formulations. Pharm. World Sci. 18:97-104 (1996).

19. J. Borovicka, R. Lehmann, P. Kunz, R. Fraser, C. Kreiss, G. Crelier, P. Boesiger, G. A. Spinas, M. Fried, and W. Schwizer. Evaluation of gastric emptying and motility in diabetic gastroparesis with magnetic resonance imaging: effects of cisapride. Am. J. Gastroenterol. 94:2866-2873 (1999).

20. L. Marciani, P. Young, J. Wright, R. J. Moore, D. F. Evans, R. C. Spiller, and P. A. Gowland. Echoplanar imaging in GI clinical practice: assessment of gastric emptying and antral motility in four patients. J. Magn. Reson. Imaging 12:343-346 (2000).

21. T. Bach-Gansmo. Ferrimagnetic susceptibility contrast agents. Acta Radiol. Suppl. 387:1-30 (1993).

22. W. K. Johnson, C. Stoupis, G. M. Torres, E. B. Rosenberg, and P. R. Ros. Superparamagnetic iron oxide (SPIO) as an oral contrast agent in gastrointestinal (GI) magnetic resonance imaging (MRI): comparison with state-of-the-art computed tomography (CT). Magn. Reson. Imaging 14:43-49 (1996).

23. C. E. Sjogren, C. Johansson, A. Naevestad, P. C. Sontum, K. Briley-Saebo, and A. K. Fahlvik. Crystal size and properties of superparamagnetic iron oxide (SPIO) particles. Magn. Reson. Imaging 15:55-67 (1997).

24. P. A. Rinck and R. N. Muller. Field strength and dose dependence of contrast enhancement by gadolinium-based MR contrast agents. Eur. Radiol. 9:998-1004 (1999).

25. M. A. Patak, D. Weishaupt, J. M. Frohlich, and J. F. Debatin Sequential fast 3D MRI following oral ingestion of Gd-DOTA: A new means to assess intestinal transit time. J. Magn. Reson. Imaging 10:474-476 (1999).

26. L. M. Akkermans and J. W. van Isselt. Gastric motility and emptying studies with radionuclides in research and clinical settings. Dig. Dis. Sci. 39:95S-96S (1994)

27. M. J. Bruno, E. B. Haverkort, G. N. Tytgat, and D. J. van Leeuwen. Maldigestion associated with exocrine pancreatic insufficiency: implications of gastrointestinal physiology and properties of enzyme preparations for a cause-related and patient-tailored treatment. Am. J. Gastroenterol. 90:1383-1393 (1995).

28. P. G. Hillel, W. B. Tindale, C. J. Taylor, M. Frier, S. Senior, and $\mathrm{S}$. Ghosal. The use of dual-isotope imaging to compare the gastrointestinal transit of food and pancreatic enzyme pellets in cystic fibrosis patients. Nucl. Med. Commun. 19:761-769 (1998).

29. M. Anvari, M. Horowitz, R. Fraser, A. Maddox, J. Myers, J. Dent, and G. G. Jamieson. Effects of posture on gastric emptying of nonnutrient liquids and antropyloroduodenal motility. Am. J. Physiol. 268:G868-G871 (1995).

30. S. Doran, K. L. Jones, J. M. Andrews, and M. Horowitz. Effects of meal volume and posture on gastric emptying of solids and appetite. Am. J. Physiol. 275:R1712-R1718 (1998). 